\title{
SOCIOLOGIA DO CRESCIMENTO PENTECOSTAL NO BRASIL: UM BALANÇO
}

(Sociology of Pentecostal growth in Brazil: a review)

\author{
Ricardo Mariano *
}

RESUMO: O artigo apresenta um balanço sumário da teoria sociológica sobre a expansão pentecostal no Brasil. Analisa as obras mais importantes que a conformaram, sua perspectiva modernizadora e destaca as críticas que recebeu. Procura mostrar que essa teoria responsabilizou prioritariamente as transformações estruturais da sociedade pelas mudanças nas escolhas religiosas de parte dos migrantes rurais e dos estratos mais pobres da população. Por fim, apresenta a perspectiva da teoria da escolha racional da religião, que, em contraste, foca sua análise na oferta religiosa.

Palavras-Chave: Expansão pentecostal, Pentecostalismo, Sociologia da religião, Modernização, Brasil.

ABSTRACT: The article presents a summary balance of sociological theory about the Pentecostal expansion in Brazil. It analyses the most important works that led to the birth of Pentecostalism, its modernizing perspective and the criticism it has received. The article seeks to show that this theory blamed primarily the structural transformations of society through changes in religious choices by rural migrants and the poorest strata of the population. Finally, the article presents the perspective of the rational choice theory of religion, which, in contrast, focuses its analysis on the religious offering.

KeY-wORDS: Pentecostal growth, Pentecostalism, Sociology of religion, Modernization, Brazil.

\footnotetext{
* Departamento de Ciências Sociais da PUCRS. Artigo recebido em 28/02/2011. Autor convidado.
} 


\section{A teoria sociológica funcionalista sobre a expansão pentecostal}

$\mathrm{O}$ artigo $^{1}$ apresenta um balanço sumário da teoria sociológica de matiz funcionalista sobre a expansão pentecostal no Brasil, expondo e analisando as principais obras que a conformaram. Destaca sua perspectiva centrada na teoria da modernização e as críticas de que foi objeto. Em seguida, mostra que essa teoria responsabiliza prioritariamente o processo de modernização e suas deletérias consequências socioculturais e econômicas pelas mudanças nas escolhas religiosas de parte dos migrantes rurais e dos estratos pobres da população. Com isso, o pentecostalismo aparece, acima de tudo, como uma "resposta" a problemas macroestruturais derivados das transições rural-urbano, tradicional-moderno. Por fim, apresenta a perspectiva da teoria da escolha racional da religião, que, em contraste com a ênfase teórica anterior, foca sua análise na oferta religiosa, isto é, nos efeitos da desregulação estatal da religião, da liberdade religiosa, do pluralismo religioso e do mercado religioso sobre os produtores e consumidores religiosos.

Os sociólogos Christian Lalive d'Epinay ${ }^{2}$ e Emilio Willems ${ }^{3}$ investigaram, em meados dos anos 60, o pentecostalismo chileno e brasileiro, respectivamente, e delimitaram a abordagem e os núcleos temáticos das pesquisas efetuadas sobre esse movimento religioso no Brasil e na América Latina até o final da década de 1970. Ambos inspiraram os trabalhos de Candido Procopio Ferreira de Camargo ${ }^{4}$ e de Beatriz Muniz de Souza ${ }^{5}$ a respeito das características e do crescimento do pentecostalismo no Brasil. Esses pesquisadores partilhavam a tese de que os intensos processos de mudanças sociais, culturais e econômicas ocorridos a partir da década de 1930, representados pela rápida industrialização, urbanização e migração de grandes contingentes rurais para as cidades, provocaram uma situação de anomia em parte dos migrantes e dos estratos pobres, tidos como ineptos cultural-

\footnotetext{
${ }^{1} \mathrm{O}$ presente artigo retoma análises e discussões presentes em minha tese de doutorado sobre o crescimento pentecostal no Brasil (cf. R. MARIANO, Análise sociológica do crescimento pentecostal no Brasil, Tese de doutorado em Sociologia, São Paulo: FFLCH-USP, 2001).

${ }^{2}$ C.L. D'EPINAY, O refúgio das massas, Rio de Janeiro: Paz e Terra, 1970.

${ }^{3}$ E. WILLEMS, Followers of the new faith: culture change and rise of protestantism in Brasil and Chile, Nashville: Vanderbilt University Press, 1967.

${ }^{4}$ O livro Católicos, protestantes, espíritas, organizado por Procopio Camargo, é uma obra coletiva elaborada por cinco pesquisadores: C.P.F. de CAMARGO (org.), Católicos, protestantes, espíritas, Petrópolis: Vozes, 1973; C.P.F. de CAMARGO, "Religiões em São Paulo", in J.V. MARCONDES (org.), São Paulo: Espírito, povo, instituição, São Paulo: Pioneira, 1968.

${ }^{5}$ B.M. de SOUZA, A experiência da salvação: pentecostais em São Paulo, São Paulo: Duas Cidades, 1969; B.M. de SOUZA, "Pentecostalismo", in As religiões da humanidade, vol. 4, São Paulo: Editora Abril, 1973, pp. 785-800.
} 
mente diante dos desafios da vida numa sociedade urbana em vertiginosa transformação sociocultural. Por isso, migrantes e parte dos pobres tinham necessidade de reconstruir um sistema significativo de relações primárias para ajustar-se à vida urbana. $O$ pentecostalismo aparece, nessas análises, como resposta à anomia, por recriar modalidades de contato primário preexistentes na sociedade tradicional, firmar laços de solidariedade entre os irmãos de fé, incentivar o auxílio mútuo nos planos material e espiritual, promover a participação do fiel nos cultos, reorientar sua conduta, seus valores e sua visão do mundo conforme os estritos preceitos bíblicos pregados por sua comunidade sectária, que são, segundo Willems, Camargo e Souza, funcionais em relação às normas de ação da sociedade capitalista emergente. Eles interpretaram o fluxo migratório e a rápida modernização como processos que favoreceram o êxito da prédica pentecostal. Apresento, a seguir, as perspectivas desses pesquisadores sobre a relação entre as mudanças socioculturais, a modernização econômica e a expansão pentecostal.

Em Followers of the new faith: culture change and the rise of protestantism in Brazil and Chile, o sociólogo alemão Emilio Willems ${ }^{6}$, que viveu no Brasil entre 1931 e 1949, afirma que industrialização e urbanização acarretam a crise do sistema oligárquico e da cultura tradicional, desenraizam as massas de origem rural e promovem a democratização da sociedade, fenômenos modernizantes que favorecem a apostasia religiosa, a aceitação social e a expansão do pentecostalismo. A rápida expansão das seitas pentecostais, a seu ver, se deve, fundamentalmente, à sua capacidade de suprir certas necessidades e aspirações de indivíduos desfavorecidos e desenraizados dos tradicionais modos de vida rural e de adaptá-los às mudanças socioculturais, mediante o fornecimento de novas comunidades, disciplina, valores adequados à vida nos centros urbanos, segurança psicológica e econômica, afinidade emocional, nova identidade social. Defende também a ideia de que a continuidade cultural entre catolicismo popular e pentecostalismo - que compartilham crenças em experiências místicas, possessões, milagres, espíritos do mal, feiticeiras e demônios - facilitou a transição para o pentecostalismo ${ }^{7}$.

Willems avalia que a inserção do protestantismo histórico no país constituiu uma espécie de carro-chefe do liberalismo norte-americano e desempenhou papel ativo, embora limitado, na transformação sociocultural e na modernização do país, promovidas por sua ética puritana, sua contribuição para a redefinição dos métodos pedagógicos e dos princípios e objetivos educacionais, sua difusão de noções de higiene e boa alimentação, suas modernas técnicas agrícolas.

\footnotetext{
${ }^{6}$ WILLEMS, Followers of the new faith: culture change and rise of protestantism in Brasil and Chile.

${ }^{7}$ Ibid., pp. 133-135.
} 
Quanto ao pentecostalismo, Willems destaca o relacionamento funcional entre seu crescimento e a transição da sociedade tradicional para a moderna, considera que ele favorece a modernização sociocultural e democratiza o acesso ao sagrado e à hierarquia eclesiástica, destacando a "primazia dos leigos" nas seitas pentecostais em oposição à tradição clerical católica, a paridade ética da conduta de ambos os sexos perante Deus, a mudança comportamental do crente resultante da adesão à ética religiosa.

Esboça, contudo, uma imagem fortemente negativa dos crentes pentecostais, afirmando que eles têm orgulho de ser incultos e despreparados para qualquer tarefa intelectual, não cultivam ideais de avanço econômico e profissional, são indiferentes ou antagônicos aos progressos educacionais e contentam-se meramente com a capacidade de ler a Bíblia ${ }^{8}$. Sua avaliação sobre as aspirações educacionais, econômicas e mesmo teológicas desses religiosos não correspondem à realidade atual, se é que corresponderam no passado, visto que o autor, paradoxalmente, menciona que a conversão pentecostal reflete aspiração a uma "vida melhor" e a procura de uma respeitabilidade pequeno-burguesa, busca de distinção social que se nota, por exemplo, em seus tradicionais trajes usados nos cultos: terno e gravata para os homens, vestido longo para as mulheres ${ }^{9}$.

Em O refúgio das massas, o sociólogo suíço Lalive d’Epinay afirma que “o pentecostalismo apresenta-se como resposta religiosa comunitária ao abandono de grandes camadas da população, abandono provocado pelo caráter anômico de uma sociedade em transição" da economia agrária, baseada na monocultura de exportação, para uma sociedade urbana e industrial ${ }^{10}$. A religião pentecostal, a seu ver, reconstrói a sociedade senhorial para as camadas pobres que vivem em estado de anomia e em condição marginal nas cidades, mantendo continuidades e descontinuidades com a tradição cultural chilena. Enfatiza, contudo, a continuidade cultural, ao afirmar que o pentecostalismo reproduz "o modelo paternalista de família ampliada", baseado, "como o da hacienda, sobre os conceitos antitéticos: opressão e proteção, arbitrariedade e graça. Em suma: tirania e paternalismo"11. Esse movimento religioso "inspira-se na sociedade tradicional", configura-se como "esforço de restauração" e "elemento de resistência à mudança", "apresenta-se como reconstituição especializada (se bem que puramente religiosa) de uma sociedade moribunda" e é "o herdeiro das estruturas do passado mais do que o precursor da sociedade emergente" ${ }^{\prime 12}$.

8 Ibid., pp. 136, 189, 219.

9 Ibid., pp. 130-131.

${ }^{10}$ D'EPINAY, $O$ refúgio das massas, p. 60.

11 Ibid., pp. 210-211.

12 Ibid., pp. 221, 228. 
Ao reconstruir comunidades baseadas em valores e tipos de dominação e de sociabilidade em processo de transformação e extinção, conclui-se que essa religião tende a proliferar somente enquanto não findar a transição da sociedade tradicional para a moderna. Com o triunfo desta, a anomia causada pelo processo de transição ao capitalismo deverá retroceder e, com ela, o apelo pentecostal. Juan Sepúlveda ${ }^{13}$ afirma que d'Epinay, posteriormente, reviu em parte essa tese, ao assumir que "a ideia de transição é ilusória", pois, à medida que a sociedade chilena passa a integrar o sistema capitalista mundial, "o que parecia um traço transitório de uma sociedade em mudança se torna uma característica estrutural de uma sociedade dependente. Assim, a crise a que o pentecostalismo parece oferecer resposta não é uma crise transitória, senão permanente".

Tal como Willems, d'Epinay considera que o pentecostalismo constitui uma sociedade sem classes, que, em contraste com o sacerdotalismo católico, fornece a todo fiel acesso às forças sobrenaturais e abre caminho a cada um para as funções dirigentes. Admite que o pentecostalismo ajuda o converso a livrar-se de vícios, sobretudo do alcoolismo, restaura a família e ensina uma forma de ascetismo, mas nega que tal ascetismo propicie poupança e valorização da atividade econômica ${ }^{14}$. Pois, $o$ crente pentecostal não parece "dotado do espírito de empresa e de iniciativa"; e o protestantismo, em simbiose com a cultura latino-americana tradicional, não introduz uma ética do trabalho, nem proporciona êxito socioeconômico a seus adeptos superior ao obtido pelo conjunto da população ${ }^{15}$. Recusa a extrapolação da tese weberiana sobre a afinidade entre a ética protestante e o espírito do capitalismo para a América Latina e rejeita a ideia de que a mobilidade econômica individual possa aumentar a riqueza e transformar o desenvolvimento nacional ${ }^{16}$. Acusa o pentecostalismo de omissão social, de alienação e de ser uma "força apolítica mais favorável ao passado e à ordem do que ao futuro", de preservar o tradicional "exercício de poder autocrático" do sistema oligárquico latino-americano, criando a figura do "pastor-patrão"17. Para d'Epinay, portanto, o pentecostalismo é conservador e autoritário e nada tem de modernizador e democratizante.

Segundo o sociólogo Procopio Camargo, a expansão pentecostal aproveita bem tanto os efeitos perversos da modernização capitalista quanto a bre-

\footnotetext{
13 J. SEPÚLVEDA, "El crecimiento del movimiento pentecostal en América latina”, in C. ALVAREZ (org.), Pentecostalismo y liberación: una experiencia latinoamericana, San José, Costa Rica: DEI, 1992, pp. 77-88, aqui p. 84.

14 D'EPINAY, $O$ refúgio das massas, pp. 236-239.

15 Ibid., pp. 239-240.

16 Ibid., pp. 241-246.

17 Ibid., pp. 205, 227; C.L. D’EPINAY, "Religião, espiritualidade e sociedade: estudo sociológico do pentecostalismo latino-americano", Cadernos do ISER 6 (1977) 5-10, aqui p. 10.
} 
cha aberta pela dessacralização ou secularização da Igreja Católica na segunda metade do século. Para tanto, constitui "resposta religiosa à situação de anomia e privação para segmentos populacionais desenraizados de formas tradicionais de organização econômica e social", propicia uma "reorientação da conduta, em termos sacrais, dos que se encontram despreparados para participar de modo efetivo na sociedade urbano-industrial" e desempenha funções de integração social e de natureza terapêutica ${ }^{18}$. A adesão ao pentecostalismo, porém, constitui um "mecanismo transitório" de ajustamento e integração dessa população desenraizada social e marginalizada nas cidades. Mecanismo transitório porque, adepto da teoria weberiana da secularização, concebe "o abandono da visão sacral do mundo como inerente ao avanço da vida urbana e da educação formal", segundo Paula Montero ${ }^{19}$. Por isso, 0 apelo de religiões densamente sacrais tende a minguar com o avanço do modo de vida urbano, do incremento da escolaridade e da secularização.

Camargo critica a ênfase do funcionalismo "em caracterizar o fenômeno religioso por suas funções de integração social e de conservação de valores e normas" e procura se apoiar igualmente em Weber, mas mantém-se no quadro da perspectiva funcionalista, ao incorporá-lo para compreender "as funções da religião no processo de mudança social" ${ }^{20}$, ressaltando as funções terapêuticas e de integração social do pentecostalismo.

Beatriz Muniz de Souza, em A experiência da salvação: pentecostais em São Paulo, obra baseada em tese de doutorado orientada por Camargo, avalia que o pentecostalismo ajusta os indivíduos à sociedade moderna, por substituir suas relações de contato primário presentes na sociedade tradicional, libertá-los da anomia, atribuir sentido sacral aos eventos do cotidiano e confortá-los em face das frustrações causadas por doenças e dificuldades de relacionamento social ${ }^{21}$. Souza destaca a função terapêutica, centrada nos ritos de cura divina, e a moral puritana (que prescreve ao crente como agir e se relacionar na sociedade) como fatores responsáveis pela expansão pentecostal.

No prefácio do livro de Souza ${ }^{22}$, escrito em setembro de 1968, a três meses da edição do AI-5, Procopio Camargo mostra-se otimista em relação ao potencial político do associativismo pentecostal. Afirma:

As seitas pentecostais representam, não obstante se caracterizarem por intensa sacralidade, uma versão internalizada de religião. Assim, os

${ }^{18}$ CAMARGO (org.), Católicos, protestantes, espíritas, pp. 10, 147.

${ }^{19}$ P. MONTERO, "Religiões e dilemas da sociedade brasileira", in S. MICELI (org.), O que ler na ciência social brasileira (1970-1995), São Paulo / Brasília: Editora Sumaré (ANPOCS) / CAPES, 1999, p. 354.

${ }^{20}$ CAMARGO (org.), Católicos, protestantes, espíritas, pp. 14-15, grifo meu.

${ }^{21}$ SOUZA, A experiência da salvação, p. 18.

22 Ibid. 
pentecostais abandonam a passividade da orientação de vida de tipo católico-tradicional, adotando forma religiosa que supõe: opção pessoal e voluntária; dramático senso de coerência em relação às normas e ao comportamento; participação na liturgia e diminuição da distância social entre o laicato e o clero. Estes traços constituiriam, em germe, as bases formadoras de uma consciência política independente das estruturas tradicionais e capaz de levar a uma atuação intensa ${ }^{23}$.

Contudo, em 1973, com o recrudescimento da repressão militar, Camargo reavalia sua posição, declarando que o pentecostalismo desempenha "funções eminentemente conservadoras" e que sua "alienação política" não dá "ensejo para o aparecimento de modalidades contestatórias ao status quo"24. À alienação e ao conservadorismo, acresce o caráter sectário do moralismo pentecostal, que "dirige sua crítica ao que entende por 'mundanismo' e vê no progresso, que necessariamente traz mudanças de papéis e de comportamento, um obstáculo à realização de seus padrões éticos" 25 . Como até então predominavam no pentecostalismo a passividade política, de um lado, e a inclinação a favor do regime militar, de outro, Camargo define, de forma taxativa, como conservadora a função social dessa religião. Em contraste com o ativismo político da vertente católica progressista da época, o pentecostalismo não colaborava para restabelecer a democracia.

Para a perspectiva funcionalista, os problemas sociais causados pela modernização econômica e pelas transformações socioculturais favorecem e estimulam a expansão das igrejas pentecostais. Estas constituem, sobretudo, "respostas", atuando basicamente como mecanismos de integração dos contingentes populacionais vitimados por tais processos macroestruturais. Em suma, a modernização da sociedade cria determinadas demandas sociais (de sentido, de identidade, de segurança psicológica e emocional...), que são supridas pelo pentecostalismo e que facilitam sua prédica e impulsionam seu crescimento. Tal perspectiva prioriza, assim, um tipo de explicação que trata a expansão pentecostal como variável dependente, como estando a reboque de fenômenos exteriores. Apesar disso, cabe observar, não se furta a complementar-se com explicações baseadas em fatores internos ao campo religioso, ao discorrer, por exemplo, sobre o êxito pentecostal por meio de sua acolhida comunitária, de suas funções terapêutica e "nomizadora", de seu proselitismo, de sua capacidade comunicacional, de sua flexibilidade organizacional etc. E também analisa o pentecostalismo como variável independente - embora não o faça para explicar sua expansão - toda vez que o percebe como potencial ou real agente promotor, mesmo que coadjuvante, de mudança favorável ou desfavorável à modernização e à democracia.

\footnotetext{
23 Ibid., p. 12.

${ }^{24}$ CAMARGO (org.), Católicos, protestantes, espíritas, p. 149.

25 Ibid., p. 153.
} 


\section{Críticas à explicação funcionalista}

Nos anos 70, pesquisadores passam a criticar a perspectiva funcionalista e a teoria da modernização presentes na interpretação sociológica sobre o pentecostalismo até então. Entre os principais críticos constam: Peter Fry e Gary Howe ${ }^{26}$, Rubem César Fernandes ${ }^{27}$, Rubem Alves ${ }^{28}$, Regina Novaes ${ }^{29}$, John Page ${ }^{30}$, Francisco Cartaxo Rolim ${ }^{31}$ e André Droogers ${ }^{32}$.

Peter Fry e Gary Howe ${ }^{33}$ criticam as teorias de Willems, d'Epinay, Camargo e Souza, porque: 1) "eles aduzem seus argumentos de certos estereótipos sociológicos baseados em dicotomias clássicas tais como folk-urbano, ordem-anomia, marginalização-integração"; 2) “os migrantes rurais nem sempre sofrem de profundo choque cultural, nem são totalmente ignorantes a respeito de problemas da cidade quando chegam; eles frequentemente seguem redes de parentesco"; 3) "não podemos aceitar o uso do conceito de 'integração' por causa da distinta dicotomia folk-urbano e porque ela implica que a cidade é num sentido uma entidade homogênea e consistente dentro da qual é possível se integrar"; 4) "a urbanização e a industrialização afetam o modo pelo qual qualquer indivíduo (seja ele migrante ou não) se relaciona com a sociedade à sua volta".

Rubem César Fernandes critica os trabalhos de Willems e Lalive por não demonstrarem, com dados, a "tese de que as religiões populares em expansão eram compostas sobretudo de migrantes"; enfatiza a "existência de estratificações e redes de poder bem formadas no interior das favelas" em oposição ao pressuposto da anomia do migrante; ressalta a superação da filosofia da história baseada no "esquema evolucionista do tradicional ao moderno"; questiona a aceitação acrítica da "equação Catolicismo = Tradição, Propriedade Senhorial, Patriarcalismo, Sacralização da Sociedade / Protestantismo = Modernidade, Capitalismo, Democracia, Secularização"34.

${ }^{26}$ P.H. FRY / G.N. HOWE, "Duas respostas à aflição: umbanda e pentecostalismo", Debate e Crítica 6 (1975) 75-94.

${ }^{27}$ R.C. FERNANDES, “O debate entre sociólogos a propósito dos pentecostais”, Cadernos do ISER 6 (1977).

${ }_{28}$ R.A. ALVES, "A volta do sagrado: os caminhos da sociologia da religião no Brasil”, Religião e Sociedade 3 (1978) 109-141.

${ }^{29}$ R.R. NOVAES, Os escolhidos de Deus: pentecostais, trabalhadores e cidadania, Rio de Janeiro: Marco Zero e Cadernos do ISER, 19, 1985.

30 J. PAGE, Brasil para Cristo: the cultural construction of pentecostal networks in Brazil, Tese de doutorado em antropologia, New York: New York University, 1984.

${ }^{31}$ F.C. ROLIM, Pentecostais no Brasil: uma interpretação sócio-religiosa, Rio de Janeiro: Vozes, 1985.

${ }^{32}$ A. DROOGERS, "Visões paradoxais de uma religião paradoxal: modelos explicativos do crescimento do pentecostalismo no Brasil e no Chile”, Estudos de Religião 8 (1992) 6183 [São Bernardo do Campo: IMS-Edims].

${ }^{33}$ FRY / HOWE, "Duas respostas à aflição: umbanda e pentecostalismo", pp. 84-85.

${ }^{34}$ FERNANDES, "O debate entre sociólogos a propósito dos pentecostais", pp. 54, 56-57. 
Na mesma toada, Rubem Alves ${ }^{35}$ critica tanto a abordagem funcionalista, cuja ideologia só vê 'anomia' e 'regressão' fora da integração funcional na esfera 'desenvolvida', quanto sua filosofia da história, que "vê na modernização, industrialização e secularização, processos inevitáveis e desejáveis". Conclui que as religiões populares, pentecostalismo e umbanda em especial, não podem ser interpretadas como meros mecanismos de integração do rural ao urbano. A seu ver, contudo, as seitas pentecostais "são mecanismos ideológicos de dominação", "empresas de cura divina" administradas "segundo normas empresariais da organização capitalista"36.

Em Os escolhidos de Deus: pentecostais, trabalhadores e cidadania, Regina Novaes ${ }^{37}$ relativiza "a ideia do migrante perdido na grande cidade e que encontra na associação pentecostal uma forma de substituir as redes de relações primárias deixadas no local de origem" e questiona a classificação de migrantes atribuída descuidadamente aos crentes que se converteram depois de já estarem vivendo há vários anos fora da terra natal, caso em que, mesmo se sua conversão decorresse de uma situação de anomia, ela não poderia resultar da migração em si.

John Page ${ }^{38}$ também se opõe à tese que associa migração rural-urbana, anomia, choque cultural e ruptura da comunidade pessoal à expansão pentecostal. Mostra que grande parte dos migrantes membros de quatro congregações da Igreja O Brasil para Cristo, moradores da Zona Norte do Rio de Janeiro, além de seguir redes de parentesco e amizade a fim de receber auxílio de familiares e amigos para encontrar casa e emprego, já possuía ampla experiência urbana, tendo vivido em uma ou mais cidades de pequeno e médio porte antes de migrar para a periferia carioca ${ }^{39}$. Da mesma forma, Andrew Chesnut ${ }^{40}$, em pesquisa conduzida em Belém em meados da década de 1990, conclui que a migração rural-urbana não ex-

\footnotetext{
${ }^{35}$ ALVES, "A volta do sagrado: os caminhos da sociologia da religião no Brasil”, p. 126. 36 Ibid.

${ }^{37}$ NOVAES, Os escolhidos de Deus, pp. 9, 122.

38 PAGE, Brasil para Cristo.

${ }^{39}$ Ibid., pp. 125, 135-136. Page (PAGE, Brasil para Cristo, pp. 89-140) revela que o tempo médio entre a migração para a cidade e a conversão perfazia 25,2 anos; a proporção de migrantes crentes $(79,2 \%)$ e de migrantes favelados não crentes $(82 \%)$ era praticamente idêntica; apenas 11,9\% haviam migrado sozinhos; apenas 4,4\% não conheciam ninguém no Rio antes de migrar, enquanto os demais tinham parentes $(50,6 \%)$, amigos e parentes $(21,3 \%)$, amigos $(16,3 \%)$, patrões $(6,9 \%$, caso de empregadas domésticas); $44,4 \%$ migraram para o Rio para ficar na casa de parentes, 3,8\% nas proximidades da casa de parentes, 6,3\% na casa de amigos, $1,9 \%$ na vizinhança da casa de amigos, 38,1\% foram para a casa do patrão ou ficaram em suas adjacências (empregadas domésticas); 41,9\% mudaram-se para o Rio já com emprego arranjado antecipadamente; dos que arrumaram emprego depois de chegar à cidade, 22,5\% o fizeram por intermédio de parentes e 15,6\%, de amigos.

${ }^{40}$ R.A. CHESNUT, Born again in Brazil: the pentecostal boom and the pathogens of poverty, New Brunswick / New Jersey / Londres: Rutgers University Press, 1997, p. 22.
} 
plica a afiliação evangélica, já que a maior parte de seus informantes $75,1 \%$ dos quais eram migrantes - aderiu ao pentecostalismo antes de migrar para a capital do Pará.

Em Pentecostais no Brasil: uma interpretação sócio-religiosa, Francisco Cartaxo Rolim ${ }^{41}$, escudado numa perspectiva marxista e crítico do funcionalismo, defende que o pentecostalismo constitui "resposta" aos interesses de classe das "camadas pobres". A filiação das massas pobres ao pentecostalismo resulta de sua exclusão social produzida pelo capitalis$\mathrm{mo}^{42}$. Rolim compartilha com os funcionalistas, portanto, a ideia de que a expansão pentecostal é favorecida por contextos socioeconômicos que acarretam marginalidade social e econômica. A análise funcionalista, como vimos, percebe certos efeitos perversos da modernização capitalista como condicionantes socioculturais das motivações e dos interesses religiosos dos pentecostais. Willems, d'Epinay, Camargo e Souza, contudo, priorizam, na explicação da expansão pentecostal, as mudanças socioculturais decorrentes da modernização socioeconômica, como quebra de controles normativos da estrutura social tradicional, mudanças axiológicas, perda e multiplicação de referenciais de sentido e comportamento, insegurança psicológica, privação da identidade social, anomia. Rolim, em contraste, enfatiza as esferas política e econômica, como a dominação de classes, a opressão social e patronal, a pobreza. Contudo, ambas as análises convergem ao perceberem o pentecostalismo como "resposta" (ou solução) para problemas sociais e individuais. A noção de indigência esposada por Rolim, porém, apresenta conotação política e denota a possibilidade de superação das injustiças e desigualdades sociais neste mundo pela via religiosa ${ }^{43}$ - via que nada tem de marxista. Ao passo que a noção de anomia remete para a possibilidade de o converso encontrar solução individual ou refúgio religioso para lidar com seus problemas de sentido, anomia e privação social.

André Droogers ${ }^{44}$ critica a unilateralidade das principais teorias sobre o crescimento do pentecostalismo brasileiro e chileno, derivada da parcialidade científica, das preferências ideológicas e das idiossincrasias dos pesquisadores. Propõe a elaboração de uma "abordagem eclética" que sistematize os diversos modelos teóricos - já que é "possível encontrar algo positivo em cada modelo" -, a fim de compor um "mosaico" explicativo desse fenômeno. Resta saber se é possível conciliar teorias com premissas discrepantes e antagônicas numa "abordagem eclética", sem cair em paradoxos insolúveis.

${ }^{41}$ ROLIM, Pentecostais no Brasil.

42 Ibid., p. 354.

${ }^{43}$ Daí a ênfase de Rolim (ROLIM, Pentecostais no Brasil, pp. 244-251) na presença de pentecostais nas Ligas Camponesas e em sindicatos rurais durante a ditadura militar.

${ }^{44}$ DROOGERS, "Visões paradoxais de uma religião paradoxal", pp. 62, 64, 79. 


\section{Modernização e pentecostalismo}

Apesar de forte crítica efetuada nos anos 70 e 80 à teoria funcionalista, na década seguinte pesquisadores estrangeiros, David Martin ${ }^{45}$ e David Stoll ${ }^{46}$, retomaram o núcleo central da tese sociológica que associa modernização, migração rural-urbana, anomia e conversão pentecostal.

Tongues of fire: The explosion of protestantism in Latin America, de David Martin, exerceu forte influência nas pesquisas sobre o movimento pentecostal e fomentou o interesse de pesquisadores norte-americanos pela investigação da "explosão" protestante na América Latina. Assevera que a expansão pentecostal se beneficiou da ruptura da união entre Igreja e Estado, da quebra do monopólio religioso do catolicismo, da fraqueza institucional da Igreja Católica e da permanência de uma cultura não secularizada, intensamente religiosa ${ }^{47}$. A ruptura do monopólio católico favoreceu o ingresso e a atuação de novos movimentos religiosos e viabilizou o pluralismo cultural, condição fundamental para a democratização das sociedades latino-americanas. Martin retoma o argumento central de Willems e d'Epinay, afirmando que o pentecostalismo arrebanha, sobretudo, os estratos sociais deslocados do campo e desorientados nas grandes cidades - largados à própria sorte no "mundo anômico da favela" - em função do advento do capitalismo ${ }^{48}$. Destaca como fatores cruciais para a expansão evangélica a capacidade das igrejas locais de comprometer os leigos com o trabalho proselitista e a habilidade de comunicação de seus pastores ${ }^{49}$.

A América Latina, segundo Martin, estaria passando por uma "reforma protestante", cujas implicações sociais, econômicas e políticas seriam semelhantes às ocorridas na Europa do século XVI. Pois, o pentecostalismo, a seu ver, difunde traços da cultura anglo-americana, entre eles princípios sociais fraternos, igualitários e democráticos favoráveis ao desenvolvimento individual, cultural e econômico, em detrimento da organização social hierárquica, autoritária, machista e patriarcal da cultura latino-american $a^{50}$. Por isso, $o$ avan-

${ }^{45}$ D. MARTIN, Tongues of fire: the explosion of Protestantism in Latin America, Oxford: Blackwell, 1990.

${ }^{46}$ D. STOLL, Is Latin America turning protestant?: the politics of evangelical growth, Berkeley: University of California Press, 1990.

${ }^{47}$ Martin parece ter incorporado essa ideia (e a estendido para os setores urbanos) da afirmação de Willems (WILLEMS, Followers of the new faith: culture change and rise of protestantism in Brasil and Chile, p. 37), segundo a qual a cultura camponesa do Brasil e do Chile era uma "cultura sagrada" sobre a qual a Igreja Católica, devido à sua crônica escassez de sacerdotes, detinha pouco controle. Para Willems (ibid., p. 36), os camponeses do Brasil e do Chile viviam "em um mundo encantado de espíritos do mal, poderes mágicos e santos poderosos".

${ }^{48}$ MARTIN, Tongues of fire, pp. 5, 106.

${ }^{49}$ Ibid., p. 292.

${ }^{50}$ Ibid., p. 12; D.E. DIXON, "The new protestantism in Latin America: remembering what we already know, testing what we have learned", in R.C. FERNANDES, Novo 
ço pentecostal teria o potencial de transformar a moral individual, a cultura, a política e a economia latino-americanas. Para Martin, essa religião desempenha, na América Latina, papel redentor, civilizador e modernizador, perspectiva que reproduz o tradicional ideário missionário protestante de que sua missão salvífica é também uma missão civilizadora.

Embora afirme que as evidências da relação entre pentecostalismo e sucesso econômico são recentes e fragmentárias, Martin ${ }^{51}$ defende que os indícios dessa correlação só não são mais visíveis porque a lógica cultural de participação, voluntarismo, autogoverno e iniciativa pessoal promovida pelo pentecostalismo encontra-se em estado latente nos países sul-americanos. O pentecostalismo desenvolve, em sua opinião, habilidades de expressão, oratória, organização, comunicação e liderança, estimula a participação, a iniciativa pessoal, o voluntarismo, cria estruturas terapêuticas, instituições educacionais e de lazer, inculca disciplina, ética do trabalho, sobriedade, pontualidade, honestidade, parcimônia, rejeita o álcool, o machismo e a promiscuidade masculina, promove a autoestima, o sentido de valor pessoal, constrói redes protetoras de apoio mútuo. Martin reedita, portanto, a tese weberiana que associa expansão protestante e modernidade, com a primeira reforçando o avanço da última, ao promover valores, habilidades e virtudes individuais consentâneos ao fortalecimento da democracia e da racionalidade econômica capitalista, agora na América Latina.

Em Is Latin America turning protestant?: The politics of evangelical growth, David Stoll ${ }^{52}$ investiga a expansão evangélica, principalmente, em países da América Central e a compreende como um "movimento popular", considerando incorretas as teorias conspiratórias acerca do sucesso numérico dos evangélicos na América Latina. Difundidas por membros do clero católico, inclusive no Brasil ${ }^{53}$, tais teorias afirmavam que o vertiginoso crescimento pentecostal abaixo do Rio Grande decorria, em grande medida, do aporte de grandes investimentos financeiros do governo norte-americano em projetos missionários da Direita Cristã para recrutar e alienar as camadas pobres da população, contrapô-las a grupos e partidos marxistas revolucionários e barrar o avanço da ala católica progressista e da Teologia da Libertação.

Stoll observa que as igrejas pentecostais incentivam a responsabilidade individual, promovem padrões éticos universais, reestruturam relações fa-

Nascimento: os evangélicos em casa, na igreja e na política, Rio de Janeiro: ISER (mimeo), 1996, pp. 479-492, aqui p. 480.

${ }^{51}$ MARTIN, Tongues of fire.

${ }^{52}$ STOLL, Is Latin America turning protestant?.

${ }^{53}$ Em 1984, a CNBB enviou relatório ao Vaticano no qual acusava governos de direita e a CIA de estimular a implantação e expansão de movimentos religiosos alienantes na América Latina para frear o crescimento da igreja progressista. Em 1987, os argumentos centrais dessa tese conspiratória foram reproduzidos no livro Os demônios descem do Norte, de Délcio Monteiro de Lima. 
miliares e de gênero, ajudam os pobres a reorganizar a vida, constituindo verdadeiros "veículos de sobrevivência" onde os pobres pegam carona. Quanto a isso, Cecília Mariz ${ }^{54}$, em Coping with poverty: pentecostals and christian base communities in Brazil, enfatiza, corretamente, que o pentecostalismo ajuda os fiéis a lidar com a pobreza. Pierucci e Prandi ${ }^{55}$ afirmam que os pentecostais buscam lideranças e instituições religiosas que os ajudem a organizar a própria vida, incapazes que são de fazê-lo por conta própria em razão de sua baixa renda e escolaridade. Ronaldo de Almeida ${ }^{56}$, da mesma forma, mostra a importância do associativismo religioso para as camadas mais pobres da população, destacando o papel que as igrejas pentecostais desempenham na formação de redes comunitárias de solidariedade e sociabilidade e na atenuação da vulnerabilidade social.

Não há dúvida de que o pentecostalismo cresce na pobreza ou na base da pirâmide socioeconômica. Contudo, cabe fazer um parêntese para enfatizar que a pobreza e a privação social não explicam a expansão pentecostal. Elas não criam nem expandem a necessidade de as pessoas aderirem especificamente ao pentecostalismo. Este não pode ser interpretado como mera "resposta" a fenômenos socioculturais, econômicos etc. Para compreender por que o pentecostalismo cresce mais entre os estratos pobres e socialmente mais vulneráveis da população do que as religiões concorrentes, cumpre investigar, entre outras coisas, como ele se organiza para convertê-los, o que lhes promete e oferece, como se vincula a seus interesses materiais e a suas visões de mundo, que estratégias emprega para atraí-los, recrutá-los, mobilizá-los e cativá-los ${ }^{57}$. Em suma, cabe investigar por que esse movimento religioso é mais eficiente que seus concorrentes no recrutamento dos estratos pobres.

Compostas de grupos flexíveis, nos quais a participação é voluntária e a liderança é carismática, as igrejas pentecostais - em oposição ao clericalismo católico -, segundo Stoll, adaptam-se rapidamente às mudanças sociais provocadas pela modernização capitalista e ajustam-se mais facilmente às demandas e necessidades das massas de migrantes pobres em busca de refúgio fraternal ${ }^{58}$. Baseando-se em trabalhos de Elizabeth Brusco ${ }^{59}$, aponta

\footnotetext{
${ }^{54}$ C.L. MARIZ, Coping with poverty: Pentecostals and Christian base communities in Brazil, Philadelphia: Temple University Press, 1994.

55 A.F. PIERUCCI / R. PRANDI, A realidade social das religiões no Brasil: religião, sociedade e política, São Paulo: Hucitec, 1996, p. 219.

${ }^{56}$ R. de ALMEIDA, "Religião na metrópole paulista", Revista Brasileira de Ciências Sociais 19 (2004/n.56).

${ }^{57}$ Sobre alguns dos fatores internos do crescimento pentecostal no Brasil, ver R. MARIANO, "Crescimento pentecostal no Brasil: fatores internos", Revista de Estudos da Religião Rever (2008) 68-95.

58 STOLL, Is Latin America turning protestant?, pp. 13, 331.

${ }^{59} \mathrm{E}$. BRUSCO, "The reformation of machismo: asceticism and masculinity among colombian evangelicals", in D. STOLL / V. GARRARD-BURNETT (org.), Rethinking protestantism in Latin America, Philadelphia: Temple University Press, 1993.
} 
a afiliação pentecostal como estratégia feminina para romper com a dupla moral sexual e domesticar os maridos, que, convertidos, abandonam atividades sexuais extraconjugais, deixam de beber, de fumar e de frequentar bares e passam a dedicar mais tempo à convivência com a família e a poupar recursos para o sustento familiar ${ }^{60}$.

Tal como David Martin, Virginia Garrard-Burnett ${ }^{61}$ considera que a expansão pentecostal constitui uma reforma (protestante) no sentido mais literal da palavra. Reforma religiosa, social e política da América Latina contemporânea, portadora e disseminadora dos mesmos efeitos modernizantes gerados e difundidos pelas seitas do protestantismo ascético anglo-saxão a partir do século XVI.

Em Struggle for the spirit: Religious transformation and popular culture in Brazil and Latin America, David Lehmann ${ }^{62}$ também considera que o pentecostalismo, embora fundamentalista, age como um "catalisador da modernidade" na América Latina e constitui extraordinário empreendimento de conquista cultural para tentar transformar a cultura popular brasileira e latino-americana, ancoradas tradicionalmente no catolicismo.

Como se pode observar, as principais pesquisas e reflexões sobre a expansão evangélica retomam a velha preocupação intelectual acerca da superação do Brasil arcaico, autoritário, subdesenvolvido e socialmente iníquo, temática recorrente no pensamento social brasileiro desde fins do século XIX. Mobilizadas por tal inquietação, priorizam enfoque analítico cujo objetivo central consiste em desvendar se o pentecostalismo promove ou não a modernização capitalista e a democracia.

A teoria da modernização expressa na literatura sociológica sobre o crescimento pentecostal no Brasil insere-se, sobretudo, na tradição do pensamento social brasileiro iniciada em meados dos anos 30 por Raízes do Brasil, de Sérgio Buarque de Holanda ${ }^{63}$. Essa tradição convoca Max Weber para "explicar o atraso da sociedade brasileira" e, ao mesmo tempo, para reivindicar a ruptura com nosso passado e nossas tradições, sobretudo com a herança do patrimonialismo ibérico, "como passo necessário para a conclusão dos processos de mudança social que levam ao moderno"64. A sociologia da religião elaborada para analisar a expansão pentecostal en-

\footnotetext{
${ }^{60}$ STOLL, IS Latin America turning protestant?, pp. 318-319.

${ }^{61}$ V. GARRARD-BURNETT, "Is this Latin America's reformation?", in STOLL / GARRARDBURNETT (org.), Rethinking protestantism in Latin America, pp. 199-210.

${ }^{62}$ D. LEHMANN, Struggle for the spirit: religious transformation and popular culture in Brazil and Latin America, Oxford: Polity Press, 1996, pp. 17, 225.

${ }^{63}$ S.B. de HOLANDA, Raízes do Brasil, 26 $6^{\text {a }}$ ed., São Paulo: Companhia das Letras, 1999.

${ }^{64}$ L.W. VIANNA, "Weber e a interpretação do Brasil", in J. SOUZA (org.), O malandro e o protestante: a tese weberiana e a singularidade cultural brasileira, Brasília: Editora UnB, 1999, pp. 173-193, aqui p. 174.
} 
cerra, portanto, o típico "viés desenvolvimentista e modernizador das nossas ciências sociais", para o qual nos chama a atenção Jessé Souza ${ }^{65}$. E, tal como em Raízes do Brasil, é notório seu pendor para contrapor nossa herança cultural ibérica e católica à cultura nórdica protestante, sempre ressaltando as desvantagens da primeira e os obstáculos que ela impõe à modernização e à democracia.

Cabe observar que a teoria sociológica da modernização foi formatada inicialmente nos Estados no pós-guerra e "dominou o debate macrossociológico das últimas seis décadas em todo o mundo", segundo Sérgio Costa ${ }^{66}$. Tal perspectiva teórica estabeleceu "as normas sociais, as estruturas e os valores encontrados nas sociedades denominadas ocidentais como o parâmetro universal que define o que são sociedades modernas", levando a que as sociedades não-ocidentais fossem medidas e avaliadas por tais padrões ${ }^{67}$. Foi somente a partir de meados dos anos 1990 que a interpretação eurocêntrica da modernidade típica das "teorias macrossociológicas dominantes" passou a ser criticada de "forma contundente e consistente", por meio da ideia das múltiplas modernidades, elaborada por Eisenstadt, e da noção de modernidade entrelaçada, proposta pelos estudos pós-coloniais, que solaparam a perspectiva da modernidade como um processo linear, uniforme e em expansão global ${ }^{68}$.

A perspectiva sociológica que vislumbra a existência de uma "afinidade eletiva" entre religião evangélica e modernidade capitalista foi influenciada sobretudo pela obra de Max Weber e pela atávica preocupação dos intelectuais brasileiros com a superação do Brasil arcaico, patriarcal, autoritário. Tal perspectiva sociológica, contudo, faz coro também à propaganda ideológica (que permanece forte ${ }^{69}$ ) de que o "progresso", ou o desenvolvimento

\footnotetext{
65 J. SOUZA, "A ética protestante e a ideologia do atraso brasileiro", in SOUZA (org.), $O$ malandro e o protestante, pp. 17-54, aqui p. 18.

66 S. COSTA, "Teoria por adição", in C.B. MARTINS / H.H.T.S. MARTINS (org.), Horizontes das Ciências Sociais no Brasil: Sociologia, São Paulo: Anpocs, 2010, p. 28.

67 Ibid.

68 Ibid., p. 29.

69 Tal propaganda ideológica ainda é frequentemente empregada pelas lideranças evangélicas de nosso país, que, de um lado, insistem em culpar o catolicismo pelos males brasileiros e, de outro, não se cansam de alardear as virtudes morais e econômicas do protestantismo. Vide, por exemplo, os seguintes trechos de artigo de Mary Schultze, que se identifica como "pesquisadora de religião" e cujos textos, publicados semanalmente na Folha Universal, atacam sistematicamente a Igreja Católica e apontam a obediência ao Evangelho como panaceia para os problemas dos fiéis e do país: "Por que o Brasil está em situação tão precária? Em primeiro lugar, porque foi colonizado por um país vassalo de Roma, que aqui implantou uma religião que só trouxe corrupção e miséria para o nosso povo. Em segundo lugar porque, tendo sido colonizado pelos portugueses e 'catequizado' pelos jesuítas, o povo não recebeu uma boa educação religiosa e foi amaldiçoado por causa da sua idolatria. Em terceiro lugar, porque sem conhecimento bíblico,
} 
técnico e industrial, "era monopólio das nações protestantes"70. Tal propaganda foi difundida desde as primeiras décadas do século XIX no Brasil por missionários e negociantes protestantes de origem inglesa, norte-americana e alemã.

Difundida originalmente por propagandistas protestantes na América Latina $^{71}$, a tese que associa protestantismo ao progresso econômico reiterava opiniões manifestas em debates parlamentares e na imprensa já nos anos 1830 e era compartilhada por elevado número de políticos e intelectuais liberais brasileiros ${ }^{72}$. Entre eles, destaca-se o escritor e deputado liberal alagoano Aureliano Cândido Tavares Bastos, dileto amigo dos missionários protestantes. Liberal, anticlerical e ardoroso defensor das causas protestantes, Tavares Bastos patrocinou imigrações inglesa, americana e alemã, envidou esforços para dar proteção jurídica, política e policial aos missionários evangélicos contra os ataques e interesses institucionais do clero ultramontano, defendeu a instituição do casamento civil e ampla liberdade de culto e de propaganda religiosa ${ }^{73}$. Em 1862, nas Cartas do Solitário, Tavares Bastos insistia em defender que "a solução dos problemas econômicos e de desenvolvimento do Brasil se encontravam na importação maciça de imigrantes protestantes dos estados germânicos, da Inglaterra e dos Estados Unidos"74.

Na esteira do projeto expansionista das potências capitalistas, em especial dos Estados Unidos, a propaganda, o ingresso e, em parte, a difusão do protestantismo de missão no país foram bem-sucedidos. Os imigrantes e missionários protestantes foram acolhidos pelos setores liberais da elite

\footnotetext{
o povo cresceu numa sucessão de gerações analfabetas, tanto do ponto de vista social quanto espiritual, enveredando pelo caminho da corrupção moral e espiritual, praticando os vícios típicos dos países dominados pelas falsas religiões. Enquanto a Inglaterra, a Alemanha e os Estados Unidos, para citar apenas três países, depois da Reforma Protestante se tornaram prósperos e felizes no hemisfério ocidental, o Brasil, muito mais rico em território, água e metais preciosos, continua paraplégico, depois de 500 anos. Os três países referidos, e as demais nações protestantes, desenvolveram-se por causa de um livro [a Bíblia]. Ao Brasil, foi negada a posse desse livro, que abre os olhos do povo, que o transforma em nova criatura, que o conduz à liberdade e à honestidade de caráter. Pela falta desse livro, o Brasil permaneceu na ignorância moral e religiosa, e jamais conseguiu sair da precariedade" (Folha Universal, 10/12/2000).

${ }^{70}$ D.G. VIEIRA, O protestantismo, a maçonaria e a Questão Religiosa no Brasil, Brasília: Editora UnB, 1980, pp. 51-52.

${ }^{71} \mathrm{O}$ pastor metodista James Cooley Fletcher foi, entre as décadas de 1850 e 1870, o maior propagandista religioso da ideia de que a imigração protestante era fundamental para o progresso do Brasil. No Chile, afirma d'Epinay (D'EPINAY, O refúgio das massas, p. 230), a "doutrina do progresso socioeconômico ligado ao protestantismo", "embora não ensinada oficialmente, aparece nas revistas missionárias e é consenso geral dos protestantes".

72 VIEIRA, O protestantismo, a maçonaria e a Questão Religiosa no Brasil, pp. 52, 75.

73 Ibid., pp. 95-112.

74 Ibid., p. 52.
} 
brasileira como "arautos do liberalismo e do progresso"75. Para eles, o protestantismo servia como contraponto aos privilégios das autoridades eclesiásticas católicas e à deletéria influência do catolicismo no Estado imperial e na sociedade brasileira, uma vez que o percebiam, especialmente a partir do último terço do século XIX, como uma das fontes do atraso social e econômico do Brasil.

Para pesquisadores brasileiros protestantes ou de origem protestante, porém, nada resta da velha ética e da ascese protestantes promotoras da racionalização da conduta e da modernidade ocidental no protestantismo brasileiro. Estes pesquisadores criticam seu conservadorismo teológico e sua ética pietista, acusam-no de adotar ética e mentalidade alienantes, conservadoras, fundamentalistas, dogmáticas, isolacionistas, autoritárias e pas$\operatorname{sivas}^{76}$. O protestantismo ascético descrito por Weber nem sequer aportou no Brasil, pontifica o ex-presbiteriano Rubem Alves ${ }^{77}$. A seu ver, a virulência das críticas decorre do fato de que "os cientistas que se dedicaram a fazer uma análise crítica do Protestantismo são, todos eles (na medida em que conheço), ex-pastores, ex-seminaristas, ex-líderes leigos forçados a deixar suas funções [por dirigentes protestantes que apoiavam a ditadura militar]. [...] O protestantismo é analisado como uma ideologia repressora, totalitária, capitalista, que se encontra em casa num Estado capitalista e totalitário"78.

Alheios às avaliações dos pesquisadores protestantes sobre o protestantismo brasileiro, alguns investigadores consideram que o paradigma teórico da modernização engessou o debate e tornou pouco fecunda a pesquisa sociológica sobre a expansão pentecostal. Em sua crítica aos referidos trabalhos de David Martin e David Stoll, Pablo Semán ${ }^{79}$, por exemplo, conclama

\footnotetext{
${ }^{75}$ A.G. MENDONÇA / P. VELASQUES FILHO, Introdução ao protestantismo no Brasil, São Paulo: Loyola, 1990, p. 74.

${ }^{76}$ Sobre as críticas de pesquisadores evangélicos ao protestantismo histórico, ver J.P. RAMALHO, Ideologia e prática educativa, Rio de Janeiro: Zahar, 1976; R.A. ALVES, Protestantismo e repressão, São Paulo: Ática, 1979; R.A. ALVES, Dogmatismo e tolerância, São Paulo: Paulinas, 1982; MENDONÇA / VELASQUES FILHO, Introdução ao protestantismo no Brasil; e P. FRESTON, Protestantes e política no Brasil: da Constituinte ao impeachment, Tese de Doutorado em sociologia, Campinas: IFCH-Unicamp, 1993. Quanto às críticas de sociólogos e historiadores contra a suposta relação de afinidade entre pentecostalismo e modernidade, ver D'EPINAY, $O$ refúgio das massas; J.P. BASTIAN, "La mutación del protestantismo latinoamericano: una perspectiva socio-histórica", in T. GUTIERREZ (org.), Protestantismo y cultura en América Latina: aportes y proyecciones, Quito, Equador: Clai-Cehila, 1994; e E.G. LÉONARD, O iluminismo num protestantismo de constituição recente, São Bernardo do Campo: Programa Ecumênico de Pós-Graduação em Ciências da Religião, 1988.

77 ALVES, Dogmatismo e tolerância, p. 127.

${ }^{78}$ ALVES, "A volta do sagrado: os caminhos da sociologia da religião no Brasil", pp. 134135.

${ }^{79}$ P. SEMÁN, "Para nuevas perspectivas en los estudios sobre el pentecostalismo", Newsletter de la Asociación de Cientistas Sociales de la Religión en el Mercosur (1998/ n.6).
} 
os pesquisadores do protestantismo a ultrapassar os limites reducionistas enfeixados pelo núcleo temático contido na relação entre o devir da modernidade e a esfera religiosa. Paula Montero ${ }^{80}$, da mesma forma, critica o apego dos pesquisadores do campo protestante a essa "simplificação, algumas vezes caricatural, de uma sociologia weberiana da modernização". Tendo em conta a expansão do "protestantismo à brasileira" da Igreja Universal, Montero ${ }^{81}$ argumenta que "o crescimento de um protestantismo marcadamente mágico e taumatúrgico obriga a repensar as bases da postulada relação entre protestantismo e modernidade".

\section{A ênfase analítica na oferta religiosa}

Na última década, a teoria da escolha racional da religião, cuja formação ocorre em meados dos anos 80 nos Estados Unidos, tornou-se importante chave heurística e analítica para a investigação da dinâmica do campo religioso e do crescimento institucional de grupos religiosos ${ }^{82}$. Ela opõe-se à perspectiva sociológica que deriva o crescimento religioso de mudanças macroestruturais da sociedade, tal como fizeram as teorias funcionalista e marxista em relação à expansão pentecostal no Brasil. Em seu lugar, prioriza a investigação da oferta religiosa e de sua maior ou menor regulação pelo Estado, relegando a segundo plano a investigação da religiosidade individual e de mudanças nas demandas religiosas de segmentos populacionais resultantes de transformações socioculturais, econômicas e políticas. Sua ênfase analítica na oferta religiosa parte do pressuposto de que o destino dos grupos religiosos, em campos religiosos desregulados pelo Estado ou em que imperam liberdade e pluralismo religiosos, é, sobretudo, "uma função de suas estruturas organizacionais, de seus representantes de vendas, de seus produtos e de suas técnicas de marketing"

Os expoentes dessa teoria, Rodney Stark, William Sims Bainbridge, Laurence Iannaccone e Roger Finke, defendem a ideia de que a desregulação estatal da religião favorece a expansão do pluralismo religioso e aumenta a mobilização religiosa dos agentes e grupos religiosos e, por tabela, da po-

\footnotetext{
${ }^{80}$ MONTERO, "Religiões e dilemas da sociedade brasileira", p. 356.

81 Ibid., p. 359.

${ }^{82}$ Sobre as principais ideias defendidas pela teoria da escolha racional da religião, os debates e polêmicas acadêmicos que ensejou e as críticas que recebeu, ver A. FRIGERIO, "Teorias econômicas aplicadas ao estudo da religião: em direção a um novo paradigma?", BIB - Revista Brasileira de Informação Bibliográfica em Ciências Sociais (2000/n.50) 125-143 [Rio de Janeiro]; A. FRIGERIO, "O paradigma da escolha racional: mercado regulado e pluralismo religioso", Tempo Social - Revista de Sociologia da USP 20 (2008/ n.2) 17-39; e MARIANO, "Crescimento pentecostal no Brasil: fatores internos".

${ }^{83}$ R. WUTHNOW, "New directions in the study of religion and economic life", in N.J. SMELSER / R. SWEDBERG (org.), The Handbook of Economic Sociology, Princeton e Oxford / New York: Princeton University Press / Russell Sage Foundation, 2005, p. 615.
} 
pulação. Ferrenhos oponentes da teoria da secularização, invertem, assim, a clássica tese de Peter Berger ${ }^{84}$, segundo a qual o pluralismo religioso enfraquece a religião, seculariza a sociedade, gera ceticismo e descrença, relativiza os discursos religiosos concorrentes, reduz sua plausibilidade, tornando-os privados e subjetivos.

Em contraste com a posição de Berger, Stark e Iannaccone ${ }^{85}$ defendem que "a participação religiosa é mais alta onde um número proporcionalmente maior de empresas religiosas competem". A desregulação estatal da religião e, sobretudo, o fim de monopólios religiosos sustentados pelo Estado asseguram liberdade e tolerância religiosas e possibilitam a emergência de novos grupos religiosos e de novas religiões concorrentes. Num contexto de liberdade e de pluralismo religiosos, os diferentes grupos religiosos se veem mais ou menos compelidos a disputar mercado para sobreviver e crescer diante da concorrência, acirrando a competição, estimulando e reforçando seu ativismo e a eficiência proselitista de seus dirigentes e leigos, diversificando e ampliando o volume da oferta de bens e serviços religiosos e ajustando-a a diferentes públicos e clientelas, criando novos nichos de mercado etc. Propiciados pela desregulação estatal da religião, liberdade e pluralismo tendem a ampliar, assim, a concorrência religiosa, o dinamismo religioso, a mobilização e participação religiosa da população. Em contraste, a regulação estatal, que tanto pode reprimir, privilegiar ou suprimir determinadas religiões, tende a restringir a competição religiosa e a diversidade de opções religiosas disponíveis aos consumidores religiosos, a gerar comodismo e menor vitalidade nos produtores religiosos ${ }^{86}$. Essa corrente teórica interpreta, portanto, as variações quantitativas na atividade religiosa nos diferentes países como consequência direta das variações no vigor dos grupos religiosos, vigor que tenderá a ser maior quanto menor for a intervenção estatal no campo religioso e quanto maior for a liberdade religiosa.

A liberdade de escolha dos consumidores religiosos tende a constranger mais fortemente os grupos religiosos onde há menor regulação estatal da religião e maiores pluralismo e competição religiosos, segundo Iannaccone ${ }^{87}$. Nesse contexto pluralista e concorrencial, na defesa de seus poderes sacerdotais e interesses institucionais, as lideranças religiosas se veem impelidas

\footnotetext{
${ }^{84}$ P.L. BERGER, O Dossel Sagrado: Elementos para uma sociologia da religião, São Paulo: Paulinas, 1985.

${ }^{85}$ R. STARK / L.R. IANNACCONE, "Sociology of religion", in E.F. BORGATTA / M.L. BORGATTA (org.), Encyclopedia of Sociology, vol. 4, New York: MacMillan Publishing Company, 1992, pp. 2029-2037, aqui pp. 2031-2032.

${ }^{86}$ R. FINKE, "The consequences of religious competition: supply-side explanations for religious change", in L.A. YOUNG (org.), Rational choice theory and religion: summary and assessment, New York: Routledge, 1997, pp. 45-64, aqui pp. 49, 51.

${ }^{87}$ L.R. IANNACCONE, "Rational choice: framework for the scientific study of religion", in YOUNG (org.), Rational choice theory and religion, pp. 25-44, aqui p. 27.
} 
a fazer concessões e a moldar o conteúdo de seus bens e serviços religiosos às preferências de fiéis e clientelas flutuantes. Contudo, os constrangimentos derivados da liberdade religiosa dos indivíduos tanto podem levá-las a diversificar a oferta de seus bens e serviços religiosos como a homogeneizálos, algo imprevisto por esses pesquisadores. No campo religioso brasileiro, constituem indícios de homogeneização, por exemplo, a ênfase na cura, no louvor musical e na emoção e a cópia de práticas e estratégias proselitistas bem-sucedidas da Igreja Universal do Reino de Deus por parte de igrejas pentecostais e da própria Renovação Carismática Católica.

O foco analítico centrado na oferta religiosa procura compreender o efeito do contexto jurídico-político sobre a dinâmica da economia religiosa. Nesse intento, prioriza a análise dos efeitos do grau de regulação estatal da religião (a relação entre Igreja e Estado, religião e política, a maior ou menor liberdade de culto e de religião), da existência ou não de monopólio, do pluralismo, do mercado, da concorrência e das organizações religiosas sobre os produtores e consumidores religiosos. Tal abordagem contextual, porém, se revela deveras limitada para compreender as escolhas e os comportamentos dos produtores e consumidores religiosos.

O fato é que essa perspectiva teórica padece de inúmeras críticas, como as que seguem: 1) desconsidera, em boa parte, mediações e constrangimentos sociais, culturais, políticos, institucionais e estruturais que influenciam, moldam e limitam as preferências e escolhas religiosas individuais e coletivas; 2) desconsidera a ação orientada por valores e o "papel dos fatores afetivos, simbólicos e emocionais no desenvolvimento de identidades coletivas" 88 ; 3) hipertrofia a racionalidade instrumental dos agentes religiosos, tratando crenças, práticas e compromissos religiosos como ações autointeressadas ou que visam tão somente maximizar benefícios pessoais $^{89}$; 4) seu enfoque restringe-se às economias religiosas dominadas por religiões congregacionais que exigem exclusividade de compromisso de seus adeptos ${ }^{90}$;) peca pela parcialidade ao não incorporar, como complemento de suma importância, a análise da demanda religiosa para explicar o que se passa na denominada economia religiosa.

Um de seus principais defensores na América Latina, Alejandro Frigerio ${ }^{91}$, destaca os méritos dessa perspectiva teórica, afirmando que ela trata, por

${ }^{88}$ P.A. MELLOR, "Rational choice or sacred contagion? 'Rationality', 'non-rationality' and religion”, Social Compass 47 (2000/n.2) 273-292, aqui p. 277.

${ }^{89}$ C. JEROLMACK, "Religion, rationality, and experience: a response to the new rational choice theory of religion”, Sociological Theory 22 (2004/n.1) 140-160, aqui p. 157.

${ }^{90}$ S. SHAROT, "Beyond christianity: a critique of the rational choice theory of religion from a weberian and comparative religions perspective", Sociology of Religion 63 (2002/ n.4) $427-454$.

${ }^{91}$ FRIGERIO, "Teorias econômicas aplicadas ao estudo da religião: em direção a um novo paradigma?", p. 132. 
definição, como racionais escolhas e comportamentos religiosos, em vez de cair em preconceitos presentes, por exemplo, em interpretações marxistas e freudianas do fenômeno religioso, que os analisam como opiáceos, irracionais e produtos da ignorância, de anomia e de crises sociais.

A ênfase na oferta religiosa tem como mérito, também, permitir focar a investigação no que as igrejas pentecostais fazem efetivamente para crescer - considerando-se o contexto de regulação estatal da religião e os constrangimentos singulares propiciados pela liberdade dos agentes religiosos, pelo pluralismo e pelo mercado religioso -, visando compreender por que muitas crescem pouco, por que algumas decrescem e perecem e por que outras granjeiam extraordinárias taxas de crescimento de membros, congregações, templos, além de visibilidade pública, emissoras de rádio e TV, representantes parlamentares etc. Assim, a pesquisa pode se concentrar em verificar o que elas fazem - e se e como e por que o fazem - para enfrentar a concorrência, evangelizar, melhorar a eficácia proselitista em certos nichos de mercado, formar pastores e dilatar seu número, abrir novas frentes de missão e evangelização, aumentar o compromisso religioso dos adeptos, ajustar o discurso e os ritos religiosos a interesses e demandas dos leigos, ampliar e diversificar a oferta de bens e serviços mágico-religiosos, estender a captação de recursos, empregar técnicas publicitárias, estratégias de marketing e métodos modernos de gestão e organização.

Não é à toa que se tende a priorizar a análise de fatores internos ao campo religioso quando se procura compreender o acelerado crescimento, por exemplo, da Igreja Universal do Reino de Deus, destacando determinadas ações e estratégias de seus dirigentes, como segue: 1) a funcionalidade da concentração de poder eclesiástico e de governos eclesiásticos verticais para a centralização dos recursos financeiros da denominação e para a realização de grandes investimentos em meios de comunicação de massa, construção de templos, envio de missionários e abertura de novos campos de missão, sustento de amplo número de pastores trabalhando em tempo integral; 2) a racionalização empresarial da gestão e da organização institucional; 3) a formação rápida e em larga escala de pastores; 4) a opção estratégica pelo evangelismo eletrônico para amplificar a atração das massas aos cultos; 5) a hipertrofia da oferta sistemática e organizada de serviços mágicos (curas, exorcismos, libertações espirituais, ritos e promessas de prosperidade material e financeira, resolução de problemas familiares, afetivos, emocionais, psicológicos etc.) para ajustar-se a visões de mundo, interesses e demandas de largas parcelas da população e, assim, ampliar a demanda por seus bens e serviços religiosos ${ }^{92}$.

${ }^{92}$ MARIANO, "Crescimento pentecostal no Brasil: fatores internos". 
À guisa de conclusão, ainda há muito que pesquisar para compreender as enormes mutações religiosas pelas quais o país tem passado nas últimas décadas, entre as quais sobressai a vertiginosa expansão do pentecostalismo, movimento religioso que, como se sabe, é o que mais cresce no Brasil e na América Latina e, ao lado do islamismo, um dos que mais crescem no mundo. Tanto que o pentecostalismo já alcança entre 20 e $25 \%$ dos brasileiros, isto é, entre um quinto e um quarto da população, segundo estimativas dos institutos Ibope e Datafolha efetuadas durante a eleição presidencial de 2010.

A despeito das limitações teóricas das análises sociológicas sobre a expansão pentecostal, o fato é que já se percorreu longo caminho na compreensão desse fenômeno religioso. Atualmente, até por conta da ampliação de seu tamanho, de suas ramificações e de sua complexidade, as pesquisas antropológicas e sociológicas sobre essa religião no Brasil têm se tornado crescentemente mais setoriais, com escopo empírico recortando de forma mais circunscrita e especializada seus objetos de investigação. Assim, avançam as pesquisas sobre, por exemplo, seu ativismo eleitoral e políticopartidário, sua ocupação religiosa da esfera pública, sua rivalidade com grupos laicistas, sobretudo feministas e homossexuais, sua crescente presença e atuação na mídia eletrônica e seu impacto sobre o campo religioso, a democracia, a cultura, as relações de gênero, os mercados editorial, musical e fonográfico ${ }^{93}$.

O pentecostalismo constitui o fenômeno religioso mais estudado no Brasil pelas ciências sociais da religião nas últimas décadas. Considerando sua crescente relevância como movimento religioso, como força demográfica, como player político e como empreendedor midiático no país, continuará sendo objeto de grande atenção acadêmica, da imprensa e da opinião pública nacional.

${ }^{93}$ Cf. A.F. PIERUCCI / R. MARIANO, "Sociologia da religião, uma sociologia da mudança", in MARTINS / MARTINS (org.), Horizontes das Ciências Sociais no Brasil: Sociologia. 


\section{Referências bibliográficas}

ALMEIDA, R. de, “Religião na metrópole paulista”, Revista Brasileira de Ciências Sociais 19 (2004/n.56).

ALVES, R.A., "A volta do sagrado: os caminhos da sociologia da religião no Brasil", Religião e Sociedade 3 (1978) 109-141.

, Protestantismo e repressão, São Paulo: Ática, 1979.

Dogmatismo e tolerância, São Paulo: Paulinas, 1982.

BASTIAN, J.P., “La mutación del protestantismo latinoamericano: una perspectiva socio-histórica", in T. GUTIERREZ (org.), Protestantismo y cultura en América Latina: aportes y proyecciones, Quito, Equador: Clai-Cehila, 1994.

BERGER, P.L., O Dossel Sagrado: Elementos para uma sociologia da religião, São Paulo: Paulinas, 1985.

BRUSCO, E., “The reformation of machismo: asceticism and masculinity among colombian evangelicals", in D. STOLL / V. GARRARD-BURNETT (org.), Rethinking protestantism in Latin America, Philadelphia: Temple University Press, 1993.

CAMARGO, C.P.F. de, “Religiões em São Paulo”, in J.V. MARCONDES (org.), São Paulo: Espírito, povo, instituição, São Paulo: Pioneira, 1968.

(org.), Católicos, protestantes, espíritas, Petrópolis: Vozes, 1973.

CHESNUT, R.A., Born again in Brazil: the pentecostal boom and the pathogens of poverty, New Brunswick / New Jersey / Londres: Rutgers University Press, 1997.

COSTA, S., "Teoria por adição", in C.B. MARTINS / H.H.T.S. MARTINS (org.), Horizontes das Ciências Sociais no Brasil: Sociologia, São Paulo, Anpocs, 2010.

D’EPINAY, C.L., O refúgio das massas, Rio de Janeiro: Paz e Terra, 1970.

, “Religião, espiritualidade e sociedade: estudo sociológico do pentecostalismo latino-americano", Cadernos do ISER 6 (1977) 5-10.

DIXON, D.E., “The new protestantism in Latin America: remembering what we already know, testing what we have learned", in R.C. FERNANDES, Novo Nascimento: os evangélicos em casa, na igreja e na política, Rio de Janeiro: ISER (mimeo), 1996, pp. 479-492.

DROOGERS, A., “Visões paradoxais de uma religião paradoxal: modelos explicativos do crescimento do pentecostalismo no Brasil e no Chile", São Bernardo do Campo: IMS-Edims, Estudos de Religião 8 (1992) 61-83.

FERNANDES, R.C., “O debate entre sociólogos a propósito dos pentecostais”, Cadernos do ISER 6 (1977).

FINKE, R., "The consequences of religious competition: supply-side explanations for religious change", in L.A. YOUNG (org.), Rational choice theory and religion: summary and assessment, New York: Routledge, 1997, pp. 45-64. 
FRESTON, P., Protestantes e política no Brasil: da Constituinte ao impeachment, Tese de Doutorado em sociologia, Campinas: IFCH-Unicamp, 1993.

FRIGERIO, A., "Teorias econômicas aplicadas ao estudo da religião: em direção a um novo paradigma?", BIB - Revista Brasileira de Informação Bibliográfica em Ciências Sociais, Rio de Janeiro, (2000/n.50) 125-143.

“O paradigma da escolha racional: mercado regulado e pluralismo religioso", Tempo Social - Revista de Sociologia da USP 20 (2008/n.2) 17-39.

FRY, P.H. / HOWE, G.N., "Duas respostas à aflição: umbanda e pentecostalismo", Debate e Crítica 6 (1975) 75-94.

GARRARD-BURNETT, V., “Is this Latin America's reformation?”, in D. STOLL / V. GARRARD-BURNETT, Rethinking protestantism in Latin America, Philadelphia: Templo University Press, 1993, pp. 199-210.

HOLANDA, S.B. de, Raízes do Brasil, $26^{a}$ ed., São Paulo: Companhia das Letras, 1999.

IANNACCONE, L.R., "Rational choice: framework for the scientific study of religion", in L.A. YOUNG (org.), Rational choice theory and religion: summary and assessment, New York: Routledge, 1997, pp. 25-44.

JEROLMACK, C., "Religion, rationality, and experience: a response to the new rational choice theory of religion", Sociological Theory 22 (2004/n.1) 140-160.

LEHMANN, D., Struggle for the spirit: religious transformation and popular culture in Brazil and Latin America, Oxford: Polity Press, 1996.

LÉONARD, E.G., O iluminismo num protestantismo de constituição recente, São Bernardo do Campo: Programa Ecumênico de Pós-Graduação em Ciências da Religião, 1988.

LIMA, D.M. de, Os demônios descem do Norte, Rio de Janeiro: Francisco Alves, 1987.

MARIZ, C.L., Coping with poverty: pentecostals and christian base communities in Brazil, Philadelphia: Temple University Press, 1994.

MARIANO, R., Análise sociológica do crescimento pentecostal no Brasil, Tese de doutorado em Sociologia, São Paulo: FFLCH-USP, 2001.

, “Crescimento pentecostal no Brasil: fatores internos", Revista de Estudos da Religião-Rever (2008) 68-95.

, “Usos e limites da teoria da escolha racional da religião", Tempo Social - Revista de Sociologia da USP 20 (2008/n.2) 41-66.

MARTIN, D., Tongues of fire: the explosion of protestantism in Latin America, Oxford: Blackwell, 1990.

MELLOR, P.A., “Rational choice or sacred contagion? 'Rationality', 'non-rationality' and religion", Social Compass 47 (2000/n.2) 273-292.

MENDONÇA, A.G. / VELASQUES FILHO, P., Introdução ao protestantismo no Brasil, São Paulo: Loyola, 1990. 
MONTERO, P., "Religiões e dilemas da sociedade brasileira", in S. MICELI (org.), O que ler na ciência social brasileira (1970-1995), São Paulo / Brasília: Editora Sumaré (ANPOCS) / CAPES, 1999.

NOVAES, R.R., Os escolhidos de Deus: pentecostais, trabalhadores e cidadania, Rio de Janeiro: Marco Zero e Cadernos do ISER, 19 (1985).

PAGE, J., Brasil para Cristo: the cultural construction of pentecostal networks in Brazil, Tese de doutorado em antropologia, New York: New York University, 1984.

PIERUCCI, A.F. / PRANDI, R., A realidade social das religiões no Brasil: religião, sociedade e política, São Paulo: Hucitec, 1996.

PIERUCCI, A.F. / MARIANO, R., "Sociologia da religião, uma sociologia da mudança", in C.B. MARTINS / H.H.T.S. MARTINS (org.), Horizontes das Ciências Sociais no Brasil: Sociologia, São Paulo: Anpocs, 2010.

RAMALHO, J.P., Ideologia e prática educativa, Rio de Janeiro: Zahar, 1976.

ROLIM, F.C., Pentecostais no Brasil: uma interpretação sócio-religiosa, Rio de Janeiro: Vozes, 1985.

SEMÁN, P., "Para nuevas perspectivas en los estudios sobre el pentecostalismo", Newsletter de la Asociación de Cientistas Sociales de la Religión en el Mercosur (1998/n.6).

SEPÚLVEDA, J., "El crecimiento del movimiento pentecostal en América latina", in C. ALVAREZ (org.), Pentecostalismo y liberacion: una experiencia latinoamericana, San José, Costa Rica: DEI, 1992, pp. 77-88.

SHAROT, S., "Beyond christianity: a critique of the rational choice theory of religion from a weberian and comparative religions perspective", Sociology of Religion 63 (2002/n.4) 427-454.

SOUZA, B.M. de, A experiência da salvação: pentecostais em São Paulo, São Paulo: Duas Cidades, 1969.

“Pentecostalismo", in As religiões da humanidade, vol. 4, São Paulo: Editora Abril, 1973, pp. 785-800.

SOUZA, J., "A ética protestante e a ideologia do atraso brasileiro", in J. SOUZA (org.), $O$ malandro e o protestante: a tese weberiana e a singularidade cultural brasileira, Brasília: Editora UnB, 1999, pp. 17-54.

STARK, R. / IANNACCONE, L.R., “Sociology of religion”, in E.F. BORGATTA / M.L. BORGATTA (org.), Encyclopedia of Sociology, vol. 4, New York: MacMillan Publishing Company, 1992, pp. 2029-2037.

STOLL, D., Is Latin America turning protestant?: the politics of evangelical growth, Berkeley: University of California Press, 1990.

STOLL, D. / GARRARD-BURNETT, V., Rethinking protestantism in Latin America, Philadelphia: Temple University Press, 1993.

VIANNA, L.W., "Weber e a interpretação do Brasil", in J. SOUZA (org.), O malandro e o protestante: a tese weberiana e a singularidade cultural brasileira, Brasília: Editora UnB, 1999, pp. 173-193. 
VIEIRA, D.G., O protestantismo, a maçonaria e a Questão Religiosa no Brasil, Brasília: Editora UnB, 1980.

WILLEMS, E., Followers of the new faith: culture change and rise of protestantism in Brasil and Chile, Nashville: Vanderbilt University Press, 1967.

WUTHNOW, R., "New directions in the study of religion and economic life", in N.J. SMELSER / R. SWEDBERG (org.), The Handbook of Economic Sociology, Princeton e Oxford / New York: Princeton University Press / Russell Sage Foundation, 2005.

Ricardo Mariano é doutor em sociologia pela USP, pesquisador do CNPq, professor do Programa de Pós-Graduação em Ciências Sociais da PUCRS, autor do livro Neopentecostais: sociologia do novo pentecostalismo no Brasil (São Paulo: Loyola, 1999) e de diversos artigos na área de sociologia da religião.

Endereço: Rua Guararapes, 70, apto. 601 90690-340 Porto Alegre - RS e-mail: rmariano@pucrs.br 